\title{
Inflammatory biomarkers and cognitive functioning in individuals with euthymic bipolar disorder: exploratory study
}

Rebecca Strawbridge, Rowena Carter, Francesco Saldarini, Dimosthenis Tsapekos and Allan H. Young

\section{Background}

Neurobiological research frequently implicates inflammatory and neurogenic components with core aspects of bipolar disorder. Even in periods of symptom remission (euthymia), individuals with bipolar disorder experience cognitive impairments, which are increasingly being proposed as an outcome for interventions; identifying biomarkers associated with cognitive impairment in people with bipolar disorder could advance progress in this therapeutic field through identifying biological treatment targets.

\section{Aims}

We aimed to identify proteomic biomarker correlates of cognitive impairment in individuals with euthymic bipolar disorder.

\section{Method}

Forty-four adults with a bipolar disorder diagnosis in euthymia underwent a battery of cognitive assessments and provided blood for biomarkers. We examined a comprehensive panel of inflammatory and trophic proteins as putative cross-sectional predictors of cognition, conceptualised according to recommended definitions of clinically significant cognitive impairment (binary construct) and global cognitive performance (continuous measure).

A total of $48 \%$ of the sample met the criteria for cognitive impairment. Adjusting for potentially important covariates,

\section{Results}

regression analyses identified lower levels of three proteins as significantly and independently associated with cognitive deficits, according to both binary and continuous definitions (interleukin-7, vascular endothelial growth factor $\mathrm{C}$ and placental growth factor), and one positively correlated with (continuous) global cognitive performance (basic fibroblast growth factor).

\section{Conclusions}

This study identifies four candidate markers of cognitive impairment in bipolar disorder, none of which have been previously compared with cognitive function in participants with bipolar disorder. Pending replication in larger samples and support from longitudinal studies, these markers could have implications for treating cognitive dysfunction in this patient population.

\section{Keywords}

Inflammation; cognition; bipolar affective disorder; neurogenesis; biomarker.

\section{Copyright and usage}

(C) The Author(s), 2021. Published by Cambridge University Press on behalf of the Royal College of Psychiatrists. This is an Open Access article, distributed under the terms of the Creative Commons Attribution licence (http://creativecommons.org/ licenses/by/4.0/), which permits unrestricted re-use, distribution, and reproduction in any medium, provided the original work is properly cited.

\section{Neurobiological mechanisms of cognitive impairment}

\section{Cognitive impairment in BD}

Bipolar disorder is a common, complex and costly illness with a poorly defined aetiology and, despite effective treatments, ${ }^{1}$ sufferers continue to experience long-term disability and reduced quality of life. $^{2}$ The cause of disability in bipolar disorder is multifactorial and extends beyond the effect of acute manic or depressive episodes. ${ }^{3} \mathrm{~A}$ critical contributing factor to disability in bipolar disorder is cognitive impairment, which frequently persists even during periods of euthymic mood. ${ }^{4,5}$ These deleterious effects of cognitive dysfunction on quality of life are widespread, ranging from everyday psychosocial functioning (including occupational, household and social function), core illness outcomes (e.g. number and severity of affective episodes, including hospital admission rate) ${ }^{5}$ and suicidal ideation. ${ }^{6}$

The prevalence of clinically significant cognitive impairment in euthymic bipolar disorder is estimated to be between 30 and 57\%, and is found across cognitive domains of memory, attention, processing speed and executive functioning; ${ }^{7}$ however, within these rates, there is significant heterogeneity as to the severity and domain specificity of impairments experienced. ${ }^{4}$ Although some current treatments may have some protective effects on cognition (e.g. lithium, lurasidone), intervention at present does not specifically target cognitive impairment in those with bipolar disorder, despite some emerging evidence of potential cognitive interventions. ${ }^{8-10}$ However, our understanding of the physiological mechanisms underlying cognitive impairment and bipolar disorder is lacking, which hinders progress in treatment options.
Recent evidence suggests that cognitive difficulties in people with depression, ${ }^{11}$ schizophrenia, ${ }^{12}$ Parkinson's disease ${ }^{13}$ and Alzheimer's disease ${ }^{14}$ may be linked to inflammation. As with these other illnesses, bipolar disorder is understood to have an inflammatory component, with systematic reviews reporting elevated pro-inflammatory cytokines, such as tumour necrosis factor- $\alpha$ (TNF- $\alpha)$, soluble tumour necrosis factor receptor type 1 (sTNF-R1) and soluble inlerleukin-2 receptor (sIL-2R) levels in patients with manic bipolar disorder compared with controls; elevated sTNF-R1 levels in manic compared with euthymic bipolar disorder ${ }^{15}$ and elevated C-reactive protein $(\mathrm{CRP})^{16}$ and interleukin-6 $(\mathrm{IL}-6)^{17}$ levels in depression compared with euthymia. Despite this, altered immune responses have also been shown to persist even when patients are euthymic. ${ }^{16,17}$

The relationship between chronic inflammation and cognitive impairment is not fully understood, but several theories for other psychiatric illnesses have postulated that chronic inflammation results in hippocampal volume loss related to hypothalamic-pituitary-adrenal (HPA) axis dysregulation as a mechanism for poor verbal recognition memory in patients with depression. ${ }^{18}$ Microglial activation has been proposed as a potential mechanism of cognitive impairment in bipolar disorder, ${ }^{19}$ and immune-modulatory drugs have shown some promising initial results in improving cognition in schizophrenia. ${ }^{20}$ The relationship between inflammation and Alzheimer's disease has been more widely studied than 
associations in mood and psychotic disorders; in models of dementia, a neuroinflammatory state has been demonstrated to activate microglia and release cytokines, ${ }^{21}$ ultimately leading to neuronal loss and exacerbating $\mathrm{A} \beta$ and neurofibrillary pathologies. ${ }^{22,23}$ Neurogenesis is also likely to be intimately involved with these relationships, with growth factor markers being clearly associated with neurocognitive and inflammatory functions, ${ }^{24}$ and linked, alongside inflammation, with severity in mood disorders. ${ }^{25}$

\section{Biological links between affect and cognition}

With increasing evidence that inflammation plays a critical role in the development of cognitive impairment across a range of psychiatric conditions, it is imperative this is considered more closely in bipolar disorder, given the burden of illness faced by patients with bipolar disorder who experience cognitive impairment. Evidence to date implicates some of the commonly assessed inflammatory markers in cognitive dysfunction, although this pertains to a limited set of biomarkers and the relationship with affective symptoms is unclear. ${ }^{26-29}$ Because of the difficulties disentangling specific cognitive impairment from impairments arising as a result of affective symptoms, it is important that cognitive impairment that would require treatment (i.e. be persistent beyond affective episodes) is assessed in fully euthymic states. Better understanding of the underlying pathophysiology may assist in developing/repurposing new treatment compounds or advancing the optimisation of existing treatment options in the future.

To our knowledge, no studies have yet compared a comprehensive panel of proteomic inflammatory markers and growth factor proteins with clinically relevant cognitive measures in bipolar disorder; this might facilitate a broader consideration of related biological networks as cognitive correlates in clinical practice. Besides, most studies of inflammation have only adjusted for limited clinical or demographic factors in these analyses, which limits the translational utility of findings.

\section{Objectives}

This study takes a comprehensive exploration of inflammatory predictors of cognitive impairment in adults with bipolar disorder not currently experiencing an episode of depression or (hypo)mania. We examine several demographic and clinical factors alongside a wide range of inflammatory and growth factor protein markers, defining cognitive performance according to international recommendations. ${ }^{30}$

Previous evidence has suggested that elevated pro-inflammatory cytokines and/or CRP partially explain severity of cognitive impairment, but several other constructs, not always adjusted for, are known to influence inflammation and be associated with bipolar disorder. As the majority of protein markers examined in this study have not previously been assessed in association with cognitive function in individuals with bipolar disorder, this is considered an exploratory study, the results of which can be used to guide future hypothesis-driven studies.

\section{Method}

\section{Design}

This study is a secondary analysis of cross-sectional (baseline) data from the Cognitive Remediation in Bipolar (CRiB) study. ${ }^{8}$ Methodological details of the $\mathrm{CRiB}$ study have been described previously. ${ }^{8,31}$ The $\mathrm{CRiB}$ study investigated a sample of 60 participants; the present analysis focuses on a subsample of 44 individuals who provided blood for biomarker analysis $(N=44)$, which was an optional assessment in the CRiB study.

\section{Participants}

Individuals were included in the study if they had a diagnosis of bipolar disorder (type 1 or type 2), had been in a euthymic affective state for at least 1 month, were aged 18-65 years, fluent in English and did not have a current substance use or personality disorder, or an impairing organic neurological disorder. Participants already had a formal bipolar disorder diagnosis, which was validated with the MINI-International Neuropsychiatric Interview (MINI). ${ }^{32}$ The MINI was also used to ensure an absence of substance use disorders. To qualify as euthymic, participants needed to meet the Newcastle Euthymia Protocol criteria, scoring $\leq 7$ on the Hamilton Rating Scale for Depression (HRSD) ${ }^{33}$ and Young Mania Rating Scale $(\mathrm{YMRS})^{34}$ at two time points 1 week apart, covering the month before inclusion.

\section{Procedure}

The study had received prior approval from the UK's Health Research Authority and London City Road \& Hampstead NHS Research Ethics Committee (identifier 15/LO/1557; trial registration ISRCTN-32290525). Participants were recruited via community advertisement and primary and secondary care healthcare services, and all provided written informed consent before taking part. The data examined in this study was then provided in a single session, before participants were randomised to receive a cognitive remediation intervention or continue treatment as usual.

\section{Measures}

Clinical, psychosocial and demographic

Continuous variables assessed were age, body mass index, number of medications currently taken, health-related quality of life (as measured by the EuroQol-5D questionnaire ${ }^{35}$ ), number of lifetime affective episodes, psychosocial functioning (measured by the Functioning Assessment Short Test $\left(\right.$ FAST) ${ }^{36}$ ), subsyndromal symptoms of depression (measured by the $\mathrm{HRSD}^{33}$ ) and mania (measured by the YMRS ${ }^{34}$ ), anxiety symptoms (measured by the Hamilton Rating Scale for Anxiety (HRSA) ${ }^{37}$ ) and history of childhood trauma (measured by the Childhood Trauma Questionnaire $\left.(\mathrm{CTQ})^{38}\right)$. Binary variables assessed were gender (all participants identifying as male or female based on free-text self-report), type of bipolar disorder (type 1 or type 2), current physical illness (yes/ no), alcohol use (nil/low or medium/high, as per thresholds on the MINI interview ${ }^{32}$ ) and smoking (yes/no). These 'non-biological' factors were selected a priori according to their understood associations with cognition and/or inflammation, as well as availability from the primary study, and all were considered in analyses as described in the statistical analysis section below.

\section{Cognitive}

The CRiB study included measurement of a neuropsychological battery producing numerous cognitive variables, as described previously. ${ }^{8,31}$ To reduce the (already extensive) number of comparisons undertaken, two measures of cognition were computed as informed by the International Society of Bipolar Disorders Cognitive Taskforce recommendations. ${ }^{30}$ These essentially measure global cognitive performance as a continuous measure, and cognitive impairment as a classified (dichotomous) construct. ${ }^{39}$ The continuous measure of 'global' cognitive performance (higher scores indicating less impairment) is calculated from eight cognitive tests across four domains: processing speed (using the Digit Symbol Substitution Test and symbol search (Wechsler Adult Intelligence Scale $)^{40}$ ), working memory (using the digit span (Wechsler Adult Intelligence Scale $)^{40}$ ), verbal learning and memory (from the verbal paired associates tests I and II (Wechsler Memory 
Scale $)^{41}$ ), and executive functioning (from the Hotel test, ${ }^{42}$ matrix reasoning (Wechsler Abbreviated Scale of Intelligence) ${ }^{43}$ and verbal fluency F-A-S test ${ }^{44}$ ). For each test, the raw score was transformed into standardised normative scores (correcting for age and education) as per test manuals, and the composite global score was then calculated by averaging each participant's $z$-scores across individual cognitive tests. ${ }^{4}$ The binary summary variable representing clinically significant cognitive impairment ${ }^{30}$ categorises participants scoring $\geq 1$ s.d. below published norms on two or more of the aforementioned cognitive tests as impaired and others as unimpaired.

\section{Biomarker}

For each participant, $5 \mathrm{~mL}$ of blood was drawn. Plasma was obtained after centrifugation and samples were stored at -80 until thawing for assay. Plasma samples were assayed using a highsensitivity Meso Scale Discovery (MSD) V-Plex kit (Meso Scale Diagnostics, Maryland, USA) as previously. ${ }^{45}$ This kit was selected because of its ability to assess an extensive range of inflammatory and trophic proteins understood to be relevant to affective disorders and with a high detection sensitivity. ${ }^{25,45}$ The panel of protein markers comprised brain-derived neurotrophic factor (BDNF), basic fibroblast growth factor (bFGF), CRP, eotaxin, eotaxin-3, fms-like tyrosine kinase (Flt-1), intracellular adhesion module (ICAM-1), interferon- $\gamma$ (IFN- $\gamma$ ), interleukin-10 (IL-10), interleukin-12 (IL-12), interleukin-15 (IL-15), interleukin-16 (IL-16), interleukin-17 (IL-17), interleukin-1 $\alpha$ (IL-1 $\alpha$ ), IL-6, interleukin-7 (IL-7), interleukin-8 (IL-8), interferon- $\gamma$-induced protein-10 (IP-10), macrophage chemoattractant protein-1 (MCP-1), macrophage chemoattractant protein-4 (MCP-4), macrophage inflammatory protein-1 $\alpha$ (Mip- $1 \alpha$ ), macrophage inflammatory protein- $1 \beta$ (Mip$1 \beta$ ), placental growth factor (PlGF), serum amyloid-A (SAA), thymus and activation-regulated chemokine (TARC), angiopoietin-1 receptor (Tie- 2 ), TNF- $\alpha$, tumour necrosis factor- $\beta$ (TNF- $\beta$ ), vascular cell adhesion molecule-1 (VCAM-1), vascular endothelial growth factor (VEGF), vascular endothelial growth factor C (VEGF-C) and vascular endothelial growth factor D (VEGF-D). Plasma was assayed with the MSD array, according to manufacturer's manual, with seven-point standard curves run in duplicate to calculate the levels of each protein with each sample, and a notemplate control included to control for background fluorescence. The standard curves demonstrated very high concentration-fluorescence correlations $\left(r^{2}>0.99\right)$, indicating reliability. Protein levels are expressed as picograms per millilitre, unless otherwise stated.

\section{Statistical analyses}

Protein levels were transformed (log base 10) and normality of distribution assessed (via skewness and kurtosis values, visual inspection of stem and leaf diagrams and box plots in addition to the Kolmogorov-Smirnov test). Because of issues surrounding the removal of outliers, particularly in small samples, bootstrapping of 1000 samples was employed on all statistical tests instead, because in these cases outliers hold less weight without removing potentially valid data altogether, and this also has the benefit of dealing with slightly non-normally distributed variables. ${ }^{46}$ Initially, univariate indications of proteins associated with the two cognitive variables was assessed with Spearman's correlation (for global cognitive performance) and $t$-tests (for cognitive impairment). Any protein associated with either cognitive variable at $P<0.1$ ('potentially indicative') was decided a priori to be considered further as putative predictors of cognitive function in respective multivariable models. Before multivariable models, the respective univariate tests also compared the above-mentioned 'non-biological factors' selected as putative confounders with the cognitive outcomes, and with the indicated protein markers; any associated at $P<0.01$ were also included as covariates in these multiple regression analyses. Multiple regressions thus aimed to explore all potentially indicative markers (i.e. biological and non-biological factors associated with cognition at $P<0.1$ in univariate tests, as independent variables) of each cognitive outcome (dependent variable). Both linear regressions (predicting global cognitive performance) and logistic regressions (predicting impairment status) were conducted. Note that the terms 'predicting' or 'predictors' here refer to crosssectional statistical associations, rather than longitudinal prediction. Model assumptions for collinearity were checked (HosmerLemeshow test in logistic regressions, and Durbin-Watson in linear regressions) and a $P$-value of $<0.05$ was considered nominally significant.

\section{Results}

\section{Sample characteristics}

Forty-four participants were assessed (based on protein marker availability in addition to the study eligibility criteria). Participants who were not currently well on the day of the baseline assessment rescheduled their appointment, and therefore, to our knowledge, none had a cold or current infection. Twenty-one participants were grouped as cognitively impaired (48\%) and 23 participants were grouped as unimpaired. The mean composite cognitive performance scores were $z=-0.675$ (s.d. 0.426) for the impaired group and $z=0.261$ (s.d. 0.350) for the unimpaired group (overall mean $z=-0.186$, s.d. $=0.609$ across the sample). Supplementary Tables 1 and 2 available at https://doi.org/10.1192/bjo.2021.966 contain descriptive data related to inflammation and cognition respectively. Clinical and demographic characteristics of the sample are presented in Table 1. None of the non-biological variables had any missing values. Four proteins (IFN- $\gamma$, IL-10, TARC and TNF- $\beta$ ) had $1-19 \%$ levels undetected by the assay, and these missing values were imputed with half the lower limit of detection. ${ }^{47}$ Eight proteins had $\geq 20 \%$ levels undetected by the assay (granulocyte-macrophage colony-stimulating factor, interleukin $-2 \mathrm{p} 70$, $-13,-1 \beta,-2,-4$ and -5 , and interferon- $\alpha$ ) and were excluded from analyses (see Supplementary Table 1); these rates of non-detection align with previous reports in similar samples. ${ }^{25,45} \mathrm{~A}$ total of 32 proteins were analysed.

\section{Univariate associations between proteins and cognition}

Table 2 displays the univariate associations between biomarker and cognitive variables. Twenty-three proteins were not associated at $P<0.1$ with cognitive summary measures; nine proteins were indicated as potentially associated with at least one of the cognitive variables, summarised below and in Fig. 1.

VEGF-C and IL-7 were significantly associated with both measures of cognition, with higher levels in the cognitively unimpaired group and a positive correlation with cognitive performance. The same pattern was observed for bFGF, although the association with the group was non-significant at $P<0.05$. IL-16 was also positively correlated with continuous performance, but not to a significant extent with impairment group. PlGF was also higher in the cognitively unimpaired group, but not correlated to a significant extent with continuous performance. Three further markers were non-significantly $(P<0.1)$ higher in participants without cognitive impairment (BDNF, TNF- $\beta$, Mip-1 $\beta$ ). IL- 6 was the only marker found to be higher in participants with cognitive impairment, although the association did not meet the threshold for statistical significance.

Because of the number of comparisons, the above analyses are to be interpreted as only preliminary, non-inferential indications. 


\begin{tabular}{|c|c|c|c|c|}
\hline \multirow{2}{*}{\multicolumn{2}{|c|}{ Characteristics }} & \multirow[b]{2}{*}{ All, $N=44$} & \\
\hline & & & Impaired, $n=21$ & Unimpaired, $n=23$ \\
\hline \multicolumn{5}{|l|}{ Continuous measures, mean (s.d.) } \\
\hline \multicolumn{2}{|l|}{ Age } & $43.7(12.8)$ & $44.3(13.0)$ & $43.9(13.2)$ \\
\hline \multicolumn{2}{|l|}{ Number of medications currently taken } & $3.7(2.2)$ & $3.4(2.0)$ & $3.0(2.4)$ \\
\hline \multicolumn{2}{|l|}{$B M I^{\mathrm{a}}$} & $27.8(6.1)$ & $28.8(5.7)$ & $26.8(6.3)$ \\
\hline \multicolumn{2}{|l|}{ Health-related quality of life (EuroQol-5D score) } & $6.9(1.7)$ & $6.9(1.8)$ & $6.9(1.6)$ \\
\hline \multicolumn{2}{|l|}{ Number of episodes } & $20.7(17.2)$ & $22.4(20.1)$ & $20.3(14.8)$ \\
\hline \multicolumn{2}{|l|}{ Depressive symptoms (HRSD score) } & $4.0(2.7)$ & $4.0(2.5)$ & $4.0(3.0)$ \\
\hline \multicolumn{2}{|l|}{ Manic symptoms (YMRS score) } & $2.7(2.40)$ & $3.0(2.2)$ & $2.6(2.6)$ \\
\hline \multicolumn{2}{|l|}{ Level of functioning (FAST score) } & $20.8(9.6)$ & $24.0(9.4)$ & $17.9(9.1)$ \\
\hline \multicolumn{2}{|l|}{ Anxiety symptoms (HRSA score) } & $6.4(4.4)$ & $5.9(3.1)$ & $6.6(5.5)$ \\
\hline \multicolumn{2}{|l|}{ Childhood adverse experience (CTQ score) } & $44.0(16.8)$ & $44.8(20.6)$ & $44.2(13.3)$ \\
\hline \multicolumn{5}{|l|}{ Binary measures, $n(\%)$} \\
\hline \multirow[t]{2}{*}{ Gender } & Male & $13(29.5 \%)$ & $5(24 \%)$ & $8(35 \%)$ \\
\hline & Female & $31(70.5 \%)$ & $16(76 \%)$ & 15 (65\%) \\
\hline \multirow[t]{2}{*}{ Bipolar disorder type } & Type 1 & $26(59 \%)$ & $13(62 \%)$ & $13(57 \%)$ \\
\hline & Type 2 & $18(41 \%)$ & $8(38 \%)$ & $10(43 \%)$ \\
\hline \multirow[t]{2}{*}{ Physical illness } & No & $18(41 \%)$ & 7 (33\%) & $11(48 \%)$ \\
\hline & Yes & 26 (59\%) & $14(67 \%)$ & $12(52 \%)$ \\
\hline \multirow[t]{2}{*}{ Smoking } & No & $32(73 \%)$ & $12(57 \%)$ & $20(87 \%)$ \\
\hline & Yes & $12(27 \%)$ & $9(43 \%)$ & $3(13 \%)$ \\
\hline \multirow[t]{2}{*}{ Alcohol use ${ }^{d}$} & No/low & $26(59 \%)$ & $14(67 \%)$ & $12(52 \%)$ \\
\hline & Mid/high & $18(41 \%)$ & 7 (33\%) & $11(48 \%)$ \\
\hline \multicolumn{5}{|c|}{$\begin{array}{l}\text { BMI, body mass index; HRSD, Hamilton Rating Scale for Depression; YMRS, Young Mania Rating Scale; FAST, Functioning Assessment Short Test; HRSA, Hamilton Rating Scale for Anxiety; } \\
\text { CTQ, Childhood Trauma Questionnaire. } \\
\text { a. Data missing for two participants. No other missing data. } \\
\text { b. originally smoking coded as current/past/never, but previous smokers did not differ from those who had never smoked in any cognitive or inflammatory measure and the two were } \\
\text { pooled. } \\
\text { c. The only significant association with cognition was that participants with cognitive impairment were more frequently smokers }\left(\chi^{2}=4.91, P=0.027\right) \text {. } \\
\text { d. Alcohol use coded according to the MIN interview. Cognitive impaired/unimpaired groups were compared with participant characteristics, using } t \text {-tests (continuous) and chi-squared } \\
\text { tests (binary). Composite cognitive performance were compared with participant characteristics, using Spearman's correlation (continuous) and t-test (binary). }\end{array}$} \\
\hline
\end{tabular}

Before regression analyses, the nine indicated proteins were compared with non-biological variables, presented in Supplementary Tables 2 and 3. The only non-biological markers associated with cognition were the FAST measure of psychosocial functioning, which was tentatively and positively associated with global cognitive performance $(r=-0.275, P=0.071)$, but not impairment group; and smoking, which was more prevalent in participants grouped as cognitively impaired versus unimpaired $\left(\chi^{2}=4.91, P=0.027\right)$, but was not associated with global performance as a continuous measure. Multivariable models included FAST in all linear regressions, and smoking in all logistic regressions.

\section{Multivariable regression analyses}

Tables 3 and 4 present the results of regression models predicting, cross-sectionally, cognitive group status (logistic; Table 3) and the continuous measure of global cognitive performance (linear; Table 4) with each of the nine indicated proteins as independent variables.

As in the univariate associations, both VEGF-C and IL-7 were significantly lower in participants with poorer cognition in both cognitive outcomes $(P<0.01)$. In both logistic regressions, smoking also remained a significant predictor of impairment. IL-7 was the only significant independent predictor in the relevant linear regression, whereas VEGF-C was accompanied by FAST, which was also significant at $P<0.05$. bFGF was significantly lower $(P<$ 0.01 ) in those with poorer cognitive performance (with FAST also significant at $P<0.05$ ), but the association with impairment group in logistic regression was not significant. IL-16 did not predict better cognitive performance or unimpaired group status when considered in regressions alongside health-related quality of life, childhood trauma severity, bipolar type and FAST/smoking.

Of the four proteins (PlGF, BDNF, Mip- $1 \beta$ and TNF- $\beta$ ) that indicated a univariate association with group (higher in participants without cognitive impairment) but not continuous performance, only PlGF contributed significantly $(P<0.05)$ to both cognitive outcomes in multivariable regression models (also containing medications, health-related quality of life, gender, smoking, age and FAST). The other three biomarkers were not significantly associated with cognitive performance. BDNF and Mip- $1 \beta$ also did not predict impairment group status, but TNF- $\beta$ (alongside number of episodes and smoking) significantly predicted impairment status at $P<0.05$.

IL- 6 was the only protein indicated at $P<0.1$ as higher in the impaired versus unimpaired group. In multivariable regressions (adjusting for health-related quality of life, smoking, physical illness and FAST), this cytokine was not a significant predictor of either cognitive outcome, although was the only protein indicating an effect of medium (as opposed to small) effect size (odds ratio 3.52).

\section{Post hoc analyses}

We maximised inclusiveness of eligibility criteria for this secondary analysis because of the small sample size. This meant that, a priori, participants with autoimmune illnesses or taking anti-inflammatory medications were not excluded. However, since these clearly affect inflammatory marker levels (and also may influence cognition), these factors were considered post hoc. After data were accessed, two participants were identified who had an autoimmune condition $(n=1)$ or were taking anti-inflammatory medications $(n=2)$. Sensitivity analyses were conducted, reanalysing the above comparisons with these two participants removed. Results were largely unaffected by this (differences are described in Supplementary Table 4), with the main changes being that TNF- $\beta$ and IL-6 no longer indicated association with cognitive functioning. In the multivariable models, the same cytokines were significant as in the planned analyses, with one exception (TNF- $\beta$; significance reduced to $P=0.057$ ).

An exploratory comparison employed Spearman's correlation to indicate associations between this subset of putative biomarkers with the individual cognitive domains that comprised the cognitive 
Table 2 Univariate associations between proteins and cognitive function

\begin{tabular}{|c|c|c|c|c|c|}
\hline \multirow[b]{2}{*}{ Biomarker } & \multicolumn{3}{|c|}{$\begin{array}{l}\text { Impaired/non-impaired group } \\
\text { comparisons }\end{array}$} & \multicolumn{2}{|c|}{$\begin{array}{l}\text { Global cognitive } \\
\text { performance } \\
\text { comparisons }\end{array}$} \\
\hline & $t$-value & $P$-value & $95 \% \mathrm{Cl}$ & $r$-value & $P$-value \\
\hline \multicolumn{6}{|c|}{ Growth factors } \\
\hline BDNF & -1.948 & 0.058 & -0.311 to $0.005^{*}$ & 0.137 & 0.377 \\
\hline bFGF & -1.713 & 0.094 & -0.471 to $0.038^{*}$ & 0.333 & $0.027 * *$ \\
\hline Flt-1 & -0.490 & 0.627 & -0.062 to 0.038 & 0.182 & 0.238 \\
\hline PIGF & -2.016 & 0.050 & -0.147 to $0.000^{* *}$ & 0.212 & 0.166 \\
\hline Tie-2 & -0.934 & 0.356 & -0.116 to 0.043 & 0.070 & 0.653 \\
\hline VEGF-C & -2.152 & 0.037 & -0.269 to $-0.009^{* *}$ & 0.333 & $0.027^{* *}$ \\
\hline VEGF-D & -1.373 & 0.177 & -0.130 to 0.025 & 0.245 & 0.110 \\
\hline VEGF & -1.377 & 0.176 & -0.191 to 0.036 & 0.171 & \\
\hline \multicolumn{6}{|c|}{ Inflammatory markers } \\
\hline CRP & 0.393 & 0.697 & -0.270 to 0.401 & -0.118 & 0.445 \\
\hline Eotaxin & -0.798 & 0.429 & -0.122 to 0 & -0.0 & \\
\hline Eotaxin-3 & -0.840 & 0.406 & -0.132 to 0.054 & -0.012 & 0.940 \\
\hline ICAM-1 & 0.262 & 0.794 & -0.078 to & 0.041 & 789 \\
\hline IFN- $\gamma$ & 0.231 & 0.818 & -0.2 & 0.124 & \\
\hline IL-10 & -0.898 & 0.374 & -0.367 to & 0.074 & \\
\hline IL-12 & -1.084 & 0.285 & -0.205 to 0 . & 0.077 & 0.8 \\
\hline IL-15 & -0.973 & 0.336 & -0.058 to 0.020 & 0.162 & 0.294 \\
\hline $\mathrm{IL}-1$ & -1.556 & 0.127 & -0.146 to & 0.297 & .050 ** \\
\hline IL-17 & -0.436 & 0.665 & -0.1 & 0.032 & \\
\hline $\mathrm{IL}-1 \alpha$ & 1.000 & 0.323 & -0.114 to 0.339 & 0.228 & 136 \\
\hline IL-6 & 1.877 & 0.067 & -0.015 to $0.422^{*}$ & -0.140 & 0.366 \\
\hline IL-7 & -3.828 & $<0.001$ & -0.475 to $-0.147^{\star \star \star * *}$ & 0.395 & $0.008^{* *}$ \\
\hline |L-8 & -0.656 & 0.516 & -0.206 to 0.10 & 0.210 & 0.172 \\
\hline IP-10 & -0.099 & 0.922 & -0.147 to & -0.049 & 752 \\
\hline MCP-1 & -0.291 & 0.773 & -0.099 to 0.074 & -0.098 & 0.527 \\
\hline MCP-4 & -1.006 & 0.320 & -0.100 to 0.033 & 0.006 & 0.968 \\
\hline Mip-1 $\alpha$ & -0.433 & 0.667 & -0.122 to 0 . & -0.001 & 0.996 \\
\hline Мip-1 $\beta$ & -1.792 & 0.080 & -0.1 & 0.097 & 0.533 \\
\hline SAA & -1.441 & 0.157 & -0.4 & 0.138 & 0.372 \\
\hline TARC & -0.960 & 0.343 & -0.896 to 0.318 & 0.247 & 0.106 \\
\hline TNF- $\alpha$ & -0.331 & 0.742 & -0.125 to 0.089 & 0.076 & 0.626 \\
\hline TNF- $\beta$ & -1.841 & 0.073 & -0.436 to 0.020 * & 0.112 & 0.468 \\
\hline VCAM-1 & -0.961 & 0.342 & -0.135 to 0.048 & 0.084 & 0.590 \\
\hline \multicolumn{6}{|c|}{ 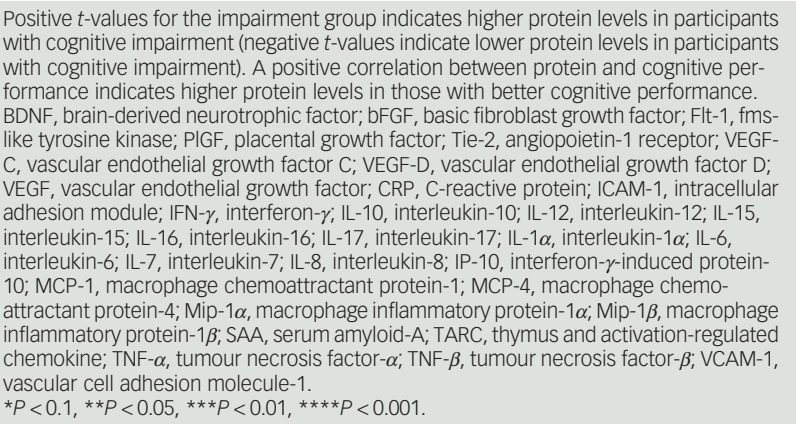 } \\
\hline
\end{tabular}

summary variables (see Supplementary Table 4). Most correlations between proteins and individual domains were small and the only associations where $P<0.01$ were IL-7 with verbal memory (Verbal Paired Associates II) and processing speed (symbol search), and VEGF-C with symbol search. Four biomarkers (IL-6, Mip-1 $\beta$, PlGF and TNF- $\beta$ ) were not significantly associated with any individual domain, and executive functioning was not significantly associated with any protein levels.

\section{Discussion}

In this sample of 44 euthymic participants with bipolar disorder, 6 of 32 examined proteins were associated with composite cognitive outcomes and 4 remained significant in regression models, after adjusting for potentially relevant non-biological covariates (both when including and excluding participants with an inflammatory condition or anti-inflammatory medication).

Three of these (VEGF-C, IL-7 and PlGF) were all lower in participants with poorer cognition as measured by both outcomes examined (clinically relevant impairment and global cognitive performance). With the same direction of effect, bFGF was predictive of global performance and, to a lesser extent, TNF- $\beta$ was predictive of impairment group status cross-sectionally.

\section{Neurobiology, mood and cognition in bipolar disorder}

It might be expected that neurobiological dysregulations in bipolar disorder would be confined to mood episodes, and most research has investigated pro-inflammatory states during mania or depression. ${ }^{48,49}$ However, elevated inflammatory ${ }^{50}$ and attenuated trophic ${ }^{51}$ biomarkers have also been reported in periods of euthymia. Within-participants comparisons of these biomarkers across different affective states are scarce, but suggest more pronounced dysregulations in mood states. ${ }^{49,52,53}$ Thus, we may have identified stronger or more frequent biomarker associations if the study been conducted when participants were experiencing an episode. However, our main interest was in cognitive associations with these biomarkers, and focusing on individuals with euthymia allowed an investigation essentially independent of mood, which has been subject to more intensive research. It is notable that none of the nine proteins assessed were correlated with subsyndromal manic, depressive or anxious symptom severity.

To date, relatively few studies have explored the relationship between inflammation and cognition, as recently reviewed. ${ }^{26} \mathrm{~A}$ 2018 study reported that in the presence of poor performance in tasks of affective processing, verbal memory, working verbal memory and executive functioning, participants with euthymic bipolar disorder had elevated plasma pro- and anti-inflammatory cytokines compared with controls, with IL- 6 being negatively correlated with global cognitive performance. ${ }^{27}$ A subsequent study reported that another prominent pro-inflammatory cytokine, TNF- $\alpha$ (but not IL-6 or other cytokines), was elevated in patients with poorer global cognition, processing speed and working memory. ${ }^{28}$ This association has recently also been reported for $\mathrm{CRP},{ }^{29}$ although the patients in the latter two studies were in variable affective states at the time of assessments, and the biomarker/ cognitive assessments were not always collected on the same day. Previous studies tended to assess cognitive function by using domain-specific outcomes, often testing several individual cognitive tests, rather than defining cognitive impairment by using consensusrecommended definitions or computing global cognition composite scores. ${ }^{30}$ Critically, they also examined a limited set of inflammatory biomarkers. In measuring a comprehensive panel of proteins, we captured a broader neurobiological impression of inflammatory and growth factor markers whose functions are understood to interact.

\section{Candidate biomarkers of cognitive dysfunction in bipolar disorder}

Our results only tentatively support an association, as identified previously, ${ }^{27}$ between elevated IL-6 and impaired cognition. Mechanistic evidence suggests that not only can this cytokine cross the blood-brain barrier, but it may be directly involved in memory consolidation. ${ }^{54}$ However, as supported by our analyses, it may be that this pro-inflammatory cytokine is more directly associated with well-being (e.g. quality of life or psychosocial functioning, which are putatively associated with reduced cognition) or affective symptoms. IL-6 has been found to rise particularly in mania, ${ }^{49}$ and may even fluctuate in association with subclinical symptoms in samples categorised as broadly euthymic. 


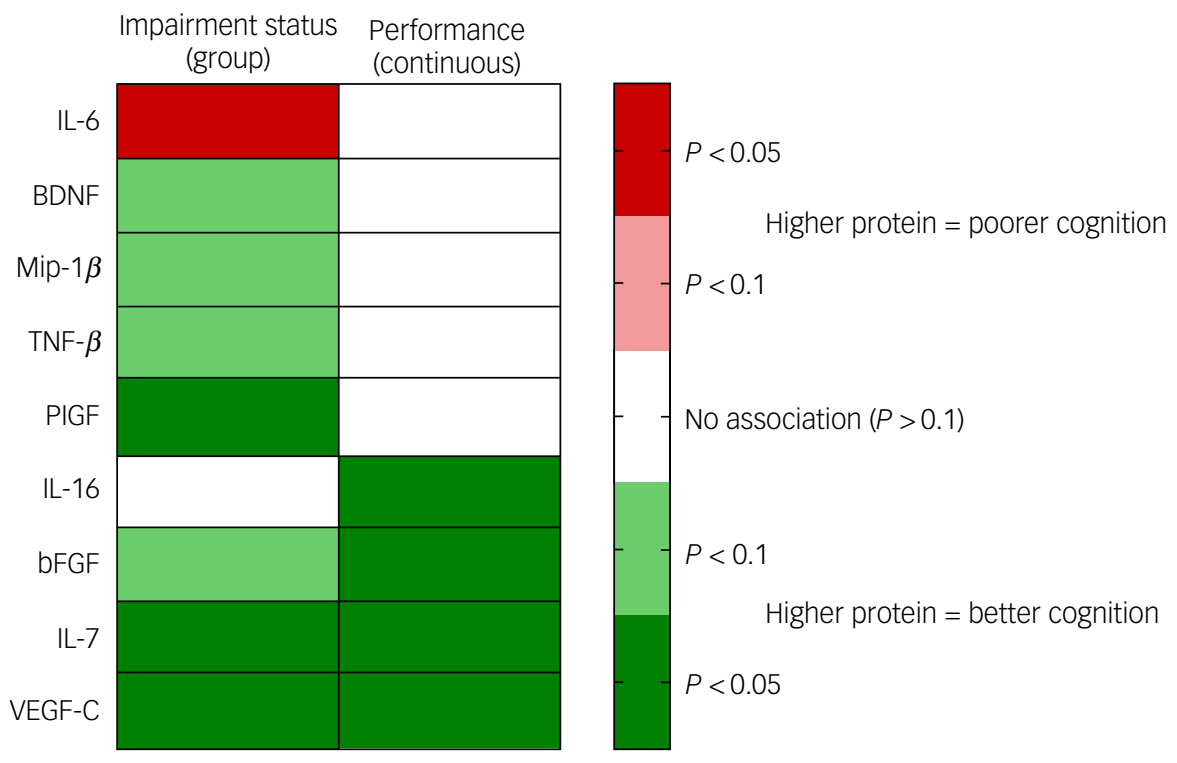

Fig. 1 Summary of univariate associations between cognitive and protein markers. BDNF, brain-derived neurotrophic factor; bFGF, basic fibroblast growth factor; IL-6, interleukin-6; IL-7, interleukin-7; IL-16, interleukin-16; Mip-1 $\beta$, macrophage inflammatory protein-1 $\beta$; PIGF, placental growth factor; TNF- $\beta$, tumour necrosis factor- $\beta$; VEGF-C, vascular endothelial growth factor $\mathrm{C}$.

BDNF is well-understood to be critical in cognitive function via neural plasticity and affected by inflammatory states, ${ }^{19}$ so it is unsurprising that this neurotrophic factor has been found as attenuated in the presence of cognitive impairment in bipolar disorder. ${ }^{55}$ Known to be particularly implicated in memory synthesis via neuronal action in the hippocampus, cortex and basal

\begin{tabular}{|c|c|c|c|c|c|c|c|}
\hline Biomarker & Model $r^{2}$ & Model $\chi^{2}$ & Model $P$ & Independent variables & Odds ratio & $95 \% \mathrm{Cl}$ & $P$-value \\
\hline \multirow[t]{3}{*}{ BDNF } & 0.307 & 11.519 & 0.009 & $\mathrm{BDNF}$ & 0.166 & $0.010-2.782$ & 0.176 \\
\hline & & & & Number of medications & 1.324 & $0.933-1.878$ & 0.100 \\
\hline & & & & Smoking & 7.381 & $1.322-41.21$ & 0.004 \\
\hline \multirow[t]{2}{*}{ bFGF } & 0.225 & 8.135 & 0.017 & bFGF & 0.252 & $0.050-1.281$ & 0.110 \\
\hline & & & & Smoking & 5.311 & $1.146-24.61$ & 0.015 \\
\hline \multirow[t]{5}{*}{$\mathrm{IL}-16^{\mathrm{a}}$} & 0.234 & 8.467 & 0.132 & IL-16 & 0.010 & $0.000-3.138$ & 0.239 \\
\hline & & & & HRQOL & 0.942 & $0.586-1.515$ & 0.845 \\
\hline & & & & CTQ & 1.007 & $0.962-1.054$ & 0.754 \\
\hline & & & & Bipolar type & 1.626 & $0.392-6.748$ & 0.539 \\
\hline & & & & Smoking & 5.336 & $1.101-25.87$ & 0.018 \\
\hline \multirow[t]{5}{*}{$I L-6^{a}$} & 0.383 & 14.895 & 0.011 & IL-6 & 3.522 & $0.267-46.45$ & 0.320 \\
\hline & & & & HRQOL & 0.453 & $0.233-0.883$ & 0.001 \\
\hline & & & & Smoking & 0.166 & $0.024-1.166$ & 0.060 \\
\hline & & & & Physical illness & 0.270 & $0.047-1.537$ & 0.099 \\
\hline & & & & FAST & 1.111 & $0.997-1.239$ & 0.020 \\
\hline \multirow[t]{3}{*}{ IL-7 } & 0.465 & 18.878 & $<0.001$ & IL-7 & 0.018 & $0.001-0.369$ & 0.005 \\
\hline & & & & Number of medications & 1.290 & $0.889-1.871$ & 0.244 \\
\hline & & & & Smoking & 7.727 & $1.142-52.27$ & 0.007 \\
\hline \multirow[t]{3}{*}{ Мip-1 $\beta$} & 0.202 & 7.216 & 0.065 & Mip-1 $\beta$ & 0.049 & $0.001-3.910$ & 0.170 \\
\hline & & & & Gender & 1.162 & $0.243-5.569$ & 0.840 \\
\hline & & & & Smoking & 4.385 & $0.946-20.33$ & 0.027 \\
\hline \multirow[t]{6}{*}{$\mathrm{PIGF}^{\mathrm{a}}$} & 0.471 & 19.162 & 0.004 & PIGF & 0.000 & $0.000-0.265$ & 0.023 \\
\hline & & & & Number of medications & 1.748 & $1.087-2.810$ & 0.013 \\
\hline & & & & $\mathrm{HRQOL}$ & 0.764 & $0.454-1.287$ & 0.371 \\
\hline & & & & Gender & 1.648 & $0.247-10.98$ & 0.605 \\
\hline & & & & Smoking & 12.26 & $1.408-106.7$ & 0.003 \\
\hline & & & & Age & 0.984 & $0.984-1.180$ & 0.100 \\
\hline \multirow[t]{3}{*}{ TNF- $\beta$} & 0.246 & 8.958 & 0.030 & TNF- $\beta$ & 0.171 & $0.025-1.194$ & 0.030 \\
\hline & & & & Number of episodes & 0.991 & 0.953-1.030 & 0.668 \\
\hline & & & & Smoking & 5.765 & $1.198-27.73$ & 0.023 \\
\hline \multirow[t]{2}{*}{ VEGF-C } & 0.297 & 11.084 & 0.004 & VEGF-C & 0.022 & $0.001-0.590$ & 0.006 \\
\hline & & & & Smoking & 7.730 & $1.329-44.94$ & 0.011 \\
\hline
\end{tabular}




\begin{tabular}{|c|c|c|c|c|c|c|c|}
\hline Biomarker & Model adjusted $r^{2}$ & Model $F$ & Model $P$ & Independent variables & Standardised $\beta$-value & $95 \% \mathrm{Cl}$ & $P$-value \\
\hline \multirow[t]{3}{*}{ BDNF } & 0.039 & 1.580 & 0.209 & BDNF & 0.096 & -0.517 to 0.954 & 0.493 \\
\hline & & & & Number of medications & -0.120 & -0.124 to 0.058 & 0.454 \\
\hline & & & & FAST & -0.213 & -0.034 to 0.007 & 0.121 \\
\hline \multirow[t]{2}{*}{ bFGF } & 0.158 & 5.035 & 0.011 & bFGF & 0.344 & $0.085-0.894$ & 0.007 \\
\hline & & & & FAST & -0.253 & -0.034 to 0.002 & 0.037 \\
\hline \multirow[t]{5}{*}{$\mathrm{IL}-16^{\mathrm{a}}$} & 0.079 & 1.741 & 0.149 & IL-16 & 0.249 & -0.390 to 2.593 & 0.194 \\
\hline & & & & HRQOL & 0.185 & -0.085 to 0.221 & 0.528 \\
\hline & & & & CTQ & -0.082 & -0.016 to 0.010 & 0.676 \\
\hline & & & & Bipolar type & -0.018 & -0.412 to 0.367 & 0.907 \\
\hline & & & & FAST & -0.380 & -0.047 to -0.002 & 0.037 \\
\hline \multirow[t]{5}{*}{ IL-6 } & 0.060 & 1.552 & 0.197 & IL-6 & -0.095 & -0.762 to 0.447 & 0.607 \\
\hline & & & & HRQOL & 0.388 & -0.005 to 0.290 & 0.103 \\
\hline & & & & Smoking & -0.063 & -0.519 to 0.349 & 0.739 \\
\hline & & & & Physical illness & -0.174 & -0.627 to 0.202 & 0.238 \\
\hline & & & & FAST & -0.412 & -0.049 to -0.003 & 0.025 \\
\hline \multirow[t]{3}{*}{ IL-7 } & 0.176 & 4.067 & 0.013 & IL-7 & 0.381 & 0.181-1.322 & 0.003 \\
\hline & & & & Number of medications & -0.060 & -0.100 to 0.067 & 0.661 \\
\hline & & & & FAST & -0.203 & -0.032 to 0.006 & 0.117 \\
\hline \multirow[t]{3}{*}{ Мip-1 $1 \beta$} & 0.035 & 1.524 & 0.223 & Mip-1 $\beta$ & 0.127 & -0.789 to 1.672 & 0.459 \\
\hline & & & & Gender & -0.047 & -0.513 to 0.388 & 0.719 \\
\hline & & & & FAST & -0.315 & -0.040 to 0.000 & 0.028 \\
\hline \multirow[t]{7}{*}{ PIGF } & 0.180 & 2.348 & 0.044 & PIGF & 0.426 & $0.298-3.861$ & 0.048 \\
\hline & & & & Number of medications & -0.183 & -0.138 to 0.037 & 0.260 \\
\hline & & & & $\mathrm{HRQOL}$ & 0.301 & -0.019 to 0.240 & 0.116 \\
\hline & & & & Gender & -0.017 & -0.432 to 0.386 & 0.919 \\
\hline & & & & Smoking & -0.730 & -0.607 to 0.286 & 0.498 \\
\hline & & & & Age & -0.063 & -0.035 to 0.001 & 0.113 \\
\hline & & & & FAST & -0.354 & -0.044 to -0.001 & 0.039 \\
\hline \multirow[t]{3}{*}{ TNF- $\beta$} & 0.050 & 1.758 & 0.171 & TNF- $\beta$ & 0.195 & -0.177 to 0.794 & 0.217 \\
\hline & & & & Number of episodes & 0.036 & -0.010 to 0.012 & 0.831 \\
\hline & & & & FAST & -0.312 & -0.040 to 0.000 & 0.031 \\
\hline \multirow[t]{2}{*}{ VEGF-C } & 0.185 & 5.866 & 0.006 & VEGF-C & 0.381 & $0.275-1.815$ & 0.006 \\
\hline & & & & FAST & -0.338 & -0.039 to -0.004 & 0.011 \\
\hline $\begin{array}{l}\text { Multivariable lir } \\
\text { 0.05. BDNF, bra } \\
\text { related quality } \\
\text { PIGF, placental } \\
\text { a. For underpo } \\
\text { were significan } \\
\text { was no longer }\end{array}$ & $\begin{array}{l}\text { regressions did not indic } \\
\text { derived neurotrophic fact } \\
\text { fe (EQ-5D score); CTQ, ch } \\
\text { wth factor; TNF- } \beta \text {, tumo } \\
\text { ed models (those contain } \\
P<0.05 \text { (between inflam } \\
\text { ificant. }\end{array}$ & $\begin{array}{l}\text { a significant } \\
\text {-AST, function } \\
\text { ood trauma S } \\
\text { ecrosis factor } \\
\text { more than on } \\
\text { ory and non-b }\end{array}$ & $\begin{array}{l}\text { ern of colline } \\
\text { npairment (Fu } \\
\text { ity (Childhooc } \\
\text { EGF-C, vascu } \\
\text { ependent var } \\
\text { gical, or cogn }\end{array}$ & $\begin{array}{l}\text { within any of the models (Durt } \\
\text { oning Assessment Short Test); } \\
\text { uma Questionnaire); IL-6, inter } \\
\text { endothelial growth factor C. } \\
\text { e per ten participants, i.e. more } \\
\text { and non-biological). The result }\end{array}$ & $\begin{array}{l}\text { Natson value between } 1 \text { and } \\
\text { F, basic fibroblast growth fa } \\
\text { in-6; IL-7, interleukin-7; Mip- } \\
\text { four in total), regressions w } \\
\text { re similar, with the exceptio }\end{array}$ & $\begin{array}{l}\text { old text indicates signif } \\
\text { IL-16, interleukin-16; H } \\
\text { lacrophage inflammato } \\
\text { e-run only containing c } \\
\text { IGF, for which the moc }\end{array}$ & $\begin{array}{l}\text { ce at } P< \\
\text {, health- } \\
\text { otein-1 } 1 \beta \text {; } \\
\text { ates that } \\
\text { a whole }\end{array}$ \\
\hline
\end{tabular}

forebrain, ${ }^{56}$ it is possible that the BDNF-cognition association in our study did not reach significance because cognition was measured as a global construct, rather than domain-specific comparisons. However, this growth factor has often been strongly correlated across a variety of cognitive domains. ${ }^{55,57}$

bFGF, another neurotrophic factor and signalling protein involved in tissue repair and angiogenesis, has been found to enhance hippocampal neurogenesis following brain injuries. ${ }^{58}$ The positive association between $\mathrm{bFGF}$ and cognitive performance was significant only for the continuous measure and not for impairment group. To our knowledge, this is the first study assessing bFGF and cognition in bipolar disorder.

VEGF growth factors are signalling proteins involved in the growth and maintenance of both vascular and neural cells, and appear protective against cognitive impairment, ${ }^{59}$ particularly in the context of Alzheimer's disease. ${ }^{60}$ Notably, VEGF-A and VEGF-D were not associated with cognitive functioning in this study, but VEGF-C was markedly higher in participants with unimpaired cognitive performance (according to both cognitive outcomes). To our knowledge, VEGF-C has not been compared with cognitive function in individuals with bipolar disorder, but our results are supported by recent preclinical evidence of decreased cerebrospinal VEGF-C having a negative effect on cognitive task performance. ${ }^{61}$

PIGF is a ligand of VEGFR and is involved in the recruitment of monocytes and macrophages, which promote vessel growth and angiogenesis. ${ }^{25}$ Similar to VEGF-C above, we identified a significant and positive association between PlGF and overall cognitive performance, although this was not apparent when assessing individual cognitive domains, and we are not aware of previous studies of PlGF in people with bipolar disorder. Unlike PlGF, individual cognitive domain examinations supported a positive relationship across multiple tests of processing speed and memory with IL-7 and VEGF-C.

Similar to the above, IL-7 (which acts as a growth factor and cytokine important for B and $\mathrm{T}$ cell development) was positively and strongly significantly associated with cognitive function in both outcomes, in this study. Our findings accord with its understood mechanisms of action, although it has not, to our knowledge, previously been studied in association with cognition in bipolar disorder.

We are also not aware of previous comparisons between lymphotoxin (or TNF- $\beta$ ) and cognition in a sample of participants with euthymic bipolar disorder. TNF- $\beta$ levels were lower in participants with cognitive impairment, which is slightly surprising given its functional proximity to TNF- $\alpha$ and sTNF receptors. which have documented involvement in both bipolar disorder and cognitive impairments, with effects in the reverse direction. ${ }^{15,26,28}$ Despite this, TNF- $\beta$ has previously been reported as attenuated in the presence of inflammatory signals in those with severe depressive episodes, ${ }^{62}$ and we highlight that the association we identified with this marker was not robust (i.e. did not persist to a significant extent after exclusion of participants whose inflammatory activity was likely influenced by a health condition or medication). 
The chemokine Mip- $1 \beta$ (CCL4) is produced in response to proinflammatory cytokines, and elevated levels have been reported in people with bipolar disorder with lower cortical thickness, ${ }^{63}$ as well as severity of cognitive impairment after stroke. ${ }^{64}$ In this study, Mip- $1 \beta$ was non-significantly lower in participants with cognitive impairment (and was also positively correlated with PlGF), which warrants further examination. It is worth noting that attenuated levels of this chemokine have been reported in people with depression (who typically present with pro-inflammatory indications) compared with healthy controls. ${ }^{65}$

When examining associations between these markers and individual cognitive domains post hoc, memory and processing speed were frequently correlated with these proteins, but a striking absence of significant relationships with executive functioning is noted, contrary to previous assertions. ${ }^{26}$

\section{Methodological considerations}

As below, we first emphasise that this exploratory study was underpowered and that numerous statistical comparisons were undertaken without adjusting for multiple testing. Therefore, clearly all nominally significant findings from the current investigation require replication in larger samples of individuals with euthymic bipolar disorder with and without cognitive impairment, and including a matched group of non-affected controls. Our study was considered an exploratory investigation of a large panel of inflammatory and trophic proteins, many of which had not been subject to examination in samples with bipolar disorder, in only 44 participants. Thus, the comparisons made were underpowered statistically, and it is possible that type 2 errors may help to explain non-significant associations in this study that contrast with established markers of impaired cognition (e.g. BDNF). Proteins identified in this study as candidate biomarkers of cognitive dysfunction need to be considered in a unified predictive model controlling for more non-biological factors, to assess the predictive value of each putative marker as well as account for their inter-associations. Our analysis tentatively suggests that modelling a binary construct (i.e. clinically significant cognitive impairment) rather than a continuous global cognitive outcome might facilitate the identification of cognitive biomarkers and subsequent neurobiological treatment targets for improving cognition in this population.

One of the methodological issues common to neurobiological and neuropsychological research is the number of data points (or markers) required to fully ascertain the complexities of constructs such as 'inflammation' or 'cognitive function'. Batteries of cognitive assessment commonly contain measurements of short-term and working memory, attention and executive functions, but there is much variation is the number and focus of tasks covering the umbrella of executive function domains. Typically, a well-rounded cognitive battery might be expected to comprise five to ten outcome variables. However, inflammatory research tends to focus on a few (two to five) traditional pro-inflammatory/T1 proteins.

Despite this, there are several other relevant constructs that we were not able to assess in this study, including waist circumference (which may better reflect adipose tissue, closely related to inflammation better than body mass index), biological gender in addition to or instead of identified gender, and use of specific medications that may have particular influence on cytokines (as opposed to general medication load). Another factor to consider is the imputation of half the limit of assay detection for proteins not detected by the MSD kit; although it is usual practice to make the assumption that this represents a low protein level present in the blood, it is indeed possible that there may have been other reasons for nondetection, and we note here that some putative biomarkers could not be assessed because of a particularly high rate of non-detection (including interleukin-1 (IL-1), which may have a prominent role in affective disorders).

As an exploratory study, we did not control for multiple comparisons, and (even limiting the number of regression models by initially conducting univariate analyses to focus on the potentially indicative proteins) several models were conducted, increasing the possibility of type 1 errors. The reporting of effect sizes in addition to $P$-values serves to aid interpretation of the effects observed. Future studies may consider these results to guide the investigation of candidate biomarkers of cognition in populations with bipolar disorder. Future work should also attempt to build on this work by assessing longitudinal relationships, as this cross-sectional study is not able to infer causality of association.

\section{Potential mechanisms for cognitive impairment in bipolar disorder}

In addition to neurogenesis, associations between reduced hippocampal volume and cognitive impairment in bipolar disorder may be mediated by inflammation or neuronal toxicity, ${ }^{66}$ although longitudinal studies are needed to ascertain temporal associations between these putatively related phenomena. Oxidative stress may also implicate mitochondrial, ${ }^{67}$ HPA axis, ${ }^{68}$ monoamine ${ }^{26}$ and/or white matter ${ }^{69,70}$ dysfunctions, all of which have been linked with bipolar disorder and cognitive difficulties. Additionally, genetic interactions may provide additional support for some of the above relationships, e.g. IL- $1^{71}$ or IL- $6^{72}$ polymorphisms.

It is worth noting that both inflammatory proteins and cognitive impairments indicate dysregulations that persist into periods of recovery, but are exacerbated during acute affective episodes. However, the proteomic markers identified relate to cognitive and affective illness characteristics that manifest in individuals with bipolar disorder, and clearly inflammatory and neurotrophic systems play a role in the key features of bipolar disorder. Relevant interventional research has focused thus far on the antidepressant and antimanic effects of anti-inflammatory medications in individuals with mood disorders, ${ }^{73}$ but the same agents have also shown pro-cognitive and neurogenic effects. ${ }^{74}$ Despite the promise of anti-inflammatory treatments for affective episodes, the use of minocycline and celecoxib was not supported in the largest study of people with bipolar disorder in a depressive episode to date, ${ }^{75}$ although there was no apparent measurement of fundamental cognitive outcomes. In addition to translational research of pharmacological treatments that regulate inflammatory activity, it may likewise be informative to assess the effects of pharmacological and psychosocial pro-cognitive interventions on inflammatory and neurotrophic protein outcomes in populations with bipolar disorder.

In conclusion, this study has provided insight into possible biological markers of cognitive impairment in individuals with bipolar disorder currently free from affective symptoms. The proteins implicated include some established markers, such as VEGF-C and bFGF, and some novel putative targets, including IL-7 and PlGF. In addition to further investigation of putative neurobiological underpinnings of cognitive dysfunction in larger and longitudinal studies, future work should consider the implications of this work for potentially detecting and treating cognitive impairment in those with bipolar disorder, which is an emerging field that is gaining momentum. ${ }^{8,25}$ Anti-inflammatory treatments appear to have some antidepressant effects, and these may also be ameliorating cognitive impairments observed in bipolar depression (where cognitive difficulties are more pronounced than in euthymia).

This exciting area of investigation is still in its infancy, and as such, more clinical studies are needed to more fully understand the nature and mechanisms underlying the relationship of 
inflammation and growth factors with cognitive deficits in bipolar disorder. This could then guide future clinical trials involving existing or potentially novel anti-inflammatory interventions addressing cognition, rather than just mood, more directly.

Rebecca Strawbridge (D), Department of Psychological Medicine, Institute of Psychiatry, Psychology \& Neuroscience, King's College London, UK; Rowena Carter, National Affective Disorders Service, South London \& Maudsley NHS Foundation Trust, UK; Francesco Saldarini (D), Department of Psychological Medicine, Institute of Psychiatry, Psychology \& Neuroscience, King's College London, UK; Dimosthenis Tsapekos (D), Department of Psychological Medicine, Institute of Psychiatry, Psychology \& Neuroscience, King's College London, UK; Allan H. Young (D), Department of Psychological Medicine, Institute of Psychiatry, Psychology \& Neuroscience, King's College London, UK; and National Affective Disorders Service, South London \& Maudsley NHS Foundation Trust, UK

Correspondence: Allan H. Young. Email: allan.young@kcl.ac.uk

First received 22 Feb 2021, final revision 25 May 2021, accepted 18 Jun 2021

\section{Supplementary material}

Supplementary material is available online at https://doi.org/10.1192/bjo.2021.966

\section{Data availability}

Data availability requests should be submitted to the corresponding author.

\section{Acknowledgements}

The authors sincerely thank all participants and contributors to the CRiB study.

\section{Author contributions}

R.S. and A.H.Y. conceptualised the study and were responsible for funding acquisition. D.T. and R.S. were responsible for data curation and acquisition. R.S. and F.S. conducted the formal anaR.S. were responsible for data curation and acquisition. R.S. and F.S. conducted the formal ana-
lysis. All authors were involved in data interpretation. R.S., D.T. and A.H.Y. were responsible for the study investigation/methodology. R.S. and R.C. Wrote the original draft of the manuscript. All authors contributed to reviewing and editing the manuscript, and gave final approval for submission. The corresponding author should be contacted for any requests for anonymised data.

\section{Funding}

This project is funded through the National Institute of Health Research (NIHR) Research for Patient Benefit programme (grant number PB-PG-0614-34075) and NIHR Maudsley Biomedical Research Centre. This article presents independent research; the funder did not have a role in the design and conduct of the study; collection, management, analysis and interpretation of the data; preparation, review or approval of the manuscript; or the decision to submit the manuscript for publication. The views expressed are those of the authors and not necessarily those of the National Health Service, the NIHR or the Department of Health and Social Care.

\section{Declaration of interest}

In the past 3 years, A.H.Y. has received honoraria for speaking from AstraZeneca, Lundbeck, Eli Lilly and Sunovion; honoraria for consulting from Allergan, Livanova, Lundbeck, Sunovion and Janssen; and research grant support from Janssen. R.S. has received an honorarium for speaking from Lundbeck. Other authors declare no conflicts of interest.

\section{References}

1 Goodwin GM. Consensus Group of the British Association for Psychopharmacology. Evidence-based guidelines for treating bipolar disorder: revised second edition-recommendations from the British Association for Psychopharmacology. J Psychopharmacol 2016; 30(6): 495-553.

2 Rosa AR, Reinares M, Michalak EE, Bonnin CM, Sole B, Franco $C$, et al. Functional impairment and disability across mood states in bipolar disorder. Value Health 2010; 13(8): 984-8.

3 Sanchez-Moreno J, Martinez-Aran A, Tabarés-Seisdedos R, Torrent C, Vieta E, Ayuso-Mateos JL. Functioning and disability in bipolar disorder: an extensive review. Psychother Psychosom 2009; 78(5): 285-97.

4 Tsapekos D, Strawbridge R, Mantingh T, Cella M, Wykes T, Young AH. Role of cognitive reserve in cognitive variability in euthymic individuals with bipolar disorder: cross-sectional cluster analysis. BJPsych Open 2020; 6(6): e133.

5 Cullen B, Ward J, Graham NA, Deary IJ, Pell JP, Smith DJ, et al. Prevalence and correlates of cognitive impairment in euthymic adults with bipolar disorder: a systematic review. J Affect Disord 2016; 205: 165-81.
6 Luo X, Zhu Y, Lu D, Zong K, Lin X. Subjective cognitive dysfunction in patients with bipolar disorder: the prevalence, related factors and effects on predicting psychosocial functioning and suicidal ideation. Psychiatry Res 2020; 284: 112669.

7 Szmulewicz AG, Samamé C, Martino DJ, Strejilevich SA. An updated review on the neuropsychological profile of subjects with bipolar disorder. Arch Clin Psychiatry 2015; 42(5): 139-46.

8 Strawbridge R, Tsapekos D, Hodsoll J, Mantingh T, Yalin N, Mccrone P, et al. Cognitive remediation therapy for bipolar disorder: a feasibility randomised controlled trial. Bipolar Disord 2021; 23(2): 196-208.

9 Miskowiak KW, Carvalho AF, Vieta E, Kessing LV. Cognitive enhancement treatments for bipolar disorder: a systematic review and methodological recommendations. Eur Neuropsychopharmacol 2016; 26(10): 1541-61.

10 Tsapekos D, Strawbridge R, Cella M, Wykes T, Young AH. Do we really need a "new" cognitive therapy for bipolar disorder? Paradigm refinements and treatment mechanisms for cognitive remediation. Bipolar Disord 2020; 22(3): 213-5.

11 Krogh J, Benros ME, Jørgensen MB, Vesterager L, Elfving B, Nordentoft M. The association between depressive symptoms, cognitive function, and inflammation in major depression. Brain Behav Immun 2014; 35: 70-6.

12 Ribeiro-Santos A, Lucio Teixeira A, Salgado JV. Evidence for an immune role on cognition in schizophrenia: a systematic review. Curr Neuropharmacol 2014; 12(3): $273-80$.

13 Lindqvist D, Hall S, Surova Y, Nielsen HM, Janelidze S, Brundin L, et al. Cerebrospinal fluid inflammatory markers in Parkinson's disease-associations with depression, fatigue, and cognitive impairment. Brain Behav Immun 2013; 33: $183-9$.

14 Whittington RA, Planel E, Terrando N. Impaired resolution of inflammation in Alzheimer's disease: a review. Front Immunol 2017; 8: 1464.

15 Munkholm K, Vinberg M, Vedel Kessing L. Cytokines in bipolar disorder: a systematic review and meta-analysis. J Affect Disord 2013; 144(1-2): 16-27.

16 Fernandes BS, Steiner J, Molendijk ML, Dodd S, Nardin P, Gonçalves C-A, et al. $C$-reactive protein concentrations across the mood spectrum in bipolar disorder: a systematic review and meta-analysis. Lancet Psychiatry 2016; 3(12): 1147-56.

17 Brietzke E, Stertz L, Fernandes BS, Kauer-Sant'Anna M, Mascarenhas M, Escosteguy Vargas A, et al. Comparison of cytokine levels in depressed, manic and euthymic patients with bipolar disorder. I Affect Disord 2009; 116(3): 214-7.

18 Shah PJ, Ebmeier KP, Glabus MF, Goodwin GM. Cortical grey matter reductions associated with treatment-resistant chronic unipolar depression. Controlled magnetic resonance imaging study. Br J Psychiatry 1998; 172: 527-32.

19 Stertz L, Magalhães PVS, Kapczinski F. Is bipolar disorder an inflammatory condition? The relevance of microglial activation. Curr Opin Psychiatry 2013; 26(1): $19-26$.

20 Levkovitz Y, Mendlovich S, Riwkes S, Braw Y, Levkovitch-Verbin H, Gal G, et al. A double-blind, randomized study of minocycline for the treatment of negative and cognitive symptoms in early-phase schizophrenia. J Clin Psychiatry 2010; 71(2): 138-49.

21 Ferreira ST, Clarke JR, Bomfim TR, De Felice FG. Inflammation, defective insulin signaling, and neuronal dysfunction in Alzheimer's disease. Alzheimers Dement 2014; 10(suppl 1): S76-83.

22 Garwood CJ, Pooler AM, Atherton J, Hanger DP, Noble W. Astrocytes are important mediators of $A \beta$-induced neurotoxicity and tau phosphorylation in primary culture. Cell Death Dis 2011; 2: e167.

23 Kitazawa M, Oddo S, Yamasaki TR, Green KN, LaFerla FM. Lipopolysaccharideinduced inflammation exacerbates tau pathology by a cyclin-dependent kinase 5-mediated pathway in a transgenic model of Alzheimer's disease. J Neurosci 2005; 25(39): 8843-53.

24 Ekdahl CT, Claasen J-H, Bonde S, Kokaia Z, Lindvall O. Inflammation is detrimental for neurogenesis in adult brain. Proc Natl Acad Sci U S A 2003; 100(23): 13632-7.

25 Pisoni A, Strawbridge R, Hodsoll J, Powell TR, Breen G, Hatch S, et al. Growth factor proteins and treatment-resistant depression: a place on the path to precision. Front Psychiatry 2018; 9: 386

26 Rosenblat JD, Brietzke E, Mansur RB, Maruschak NA, Lee $Y$, McIntyre RS. Inflammation as a neurobiological substrate of cognitive impairment in bipolar disorder: evidence, pathophysiology and treatment implications. J Affect Disord 2015; 188: 149-59.

27 Barbosa IG, de Ferreira RA, Rocha NP, Mol GC, da Mata Chiaccjio Leite F, Bauer IE, et al. Predictors of cognitive performance in bipolar disorder: the role of educational degree and inflammatory markers. J Psychiatr Res 2018; 106: $31-7$.

28 Chakrabarty T, Torres IJ, Bond DJ, Yatham LN. Inflammatory cytokines and cognitive functioning in early-stage bipolar I disorder. J Affect Disord 2019; 245: 679-85. 
29 Dickerson F, Stallings C, Origoni A, Vaughan C, Khushalani S, Yolken R. Elevated C-reactive protein and cognitive deficits in individuals with bipolar disorder. $J$ Affect Disord 2013; 150(2): 456-9.

30 Miskowiak K, Burdick KE, Martinez Aran A, Bonnin CM, Bowie CR, Carvalho AF, et al. Methodological recommendations for cognition trials in bipolar disorder by the International Society for Bipolar Disorders Targeting Cognition Task Force. Bipolar Disord 2017; 19(8): 614-26.

31 Strawbridge R, Fish J, Halari R, Hodsoll J, Reeder C, Macritchie K, et al. The Cognitive Remediation in Bipolar (CRiB) pilot study: study protocol for a randomised controlled trial. Trials 2016; 17: 371.

32 Sheehan DV, Lecrubier $\mathrm{Y}$, Sheehan $\mathrm{KH}$, Amorim $\mathrm{P}$, Janavs J, Weiller $\mathrm{E}$, et al. The Mini-International Neuropsychiatric Interview (M.I.N.I.): the development and validation of a structured diagnostic psychiatric interview for DSM-IV and ICD-10. J Clin Psychiatry 1998; 59(suppl 20): 22-33; quiz 34-57.

33 Hamilton M. A rating scale for depression. J Neurol Neurosurg Psychiatry 1960; 23: $56-62$.

34 Young RC, Biggs JT, Ziegler VE, Meyer DA. A rating scale for mania: reliability, validity and sensitivity. Br J Psychiatry 1978; 133: 429-35.

35 Dolan $\mathrm{P}$. The measurement of health-related quality of life for use in resource allocation decisions in health care. In Handbook of Health Economics, Volume 1 (eds AJ Culyer, JP Newhouse): 1723-60. Elsevier, 2000.

36 Rosa AR, Sánchez-Moreno J, Martínez-Aran A, Salamero M, Torrent C, Reinares $M$, et al. Validity and reliability of the Functioning Assessment Short Test (FAST) in bipolar disorder. Clin Pract Epidemol Ment Health 2007; 3: 5.

37 Hamilton M. The assessment of anxiety states by rating. Br J Med Psychol 1959; 32(1): $50-5$

38 Bernstein DP, Fink L, Handelsman L, Foote J, Lovejoy M, Wenzel K, et al. Initial reliability and validity of a new retrospective measure of child abuse and neglect. Am J Psychiatry 1994; 151(8): 1132-6.

39 Tsapekos D, Strawbridge R, Mantingh T, Cella M, Wykes T, Young AH. Role of cognitive reserve in cognitive variability in euthymic individuals with bipolar disorder: cross-sectional cluster analysis. BJPsych Open 2020; 6(6): e133.

40 Wechsler D. Wechsler Adult Intelligence Scale-Fourth Edition (WAIS-IV). Pearson, 2008.

41 Wechsler D. Wechsler Memory Scale_Fourth Edition (WMS-IV) Technical and Interpretive Manual. Pearson, 2009

42 Manly T, Hawkins K, Evans J, Woldt K, Robertson IH. Rehabilitation of executive function: facilitation of effective goal management on complex tasks using periodic auditory alerts. Neuropsychologia 2002; 40(3): 271-81.

43 Wechsler D. Wechsler Abbreviated Scale of Intelligence - Second Edition. Pearson, 2011.

44 Delis D, Kaplan E, Kramer J. Delis-Kaplan Executive Function System (DKEFS) Psychological Corporation, 2001.

45 Strawbridge R, Marwood L, King S, Young AH, Pariante CM, Colasanti A, et al. Inflammatory proteins and clinical response to psychological therapy in patients with depression: an exploratory study. J Clin Med 2020; 9(12): 3918.

46 Davison AC, Hinkley DV. Bootstrap Methods and Their Application. Cambridge University Press, 1997

47 Croghan CW, Egeghy PP. Methods of Dealing with Values Below the Limit of Detection Using SAS. (St. Petersburg, FL, September 22-24, 2003). Southeastern SAS User Group, 2003.

48 Barbosa IG, Bauer ME, Machado-Vieira R, Teixeira AL. Cytokines in bipolar disorder: paving the way for neuroprogression. Neural Plast 2014; 2014: 360481

49 Ortiz-Domínguez A, Hernández ME, Berlanga C, Gutiérrez-Mora D, Moreno J, Heinze G, et al. Immune variations in bipolar disorder: phasic differences. Bipolar Disord 2007; 9(6): 596-602.

50 Doganavsargil-Baysal O, Cinemre B, Aksoy UM, Akbas H, Metin O, Fettahoglu C et al. Levels of TNF- $\alpha$, soluble TNF receptors (STNFR1, STNFR2), and cognition in bipolar disorder. Hum Psychopharmacol Clin Exp 2013; 28(2): 160-7.

51 Monteleone P, Serritella C, Martiadis V, Maj M. Decreased levels of serum brainderived neurotrophic factor in both depressed and euthymic patients with unipolar depression and in euthymic patients with bipolar I and II disorders. Bipolar Disord 2008; 10(1): 95-100.

52 Kapczinski F, Dal-Pizzol F, Teixeira AL, Magalhaes PVS, Kauer-Sant'Anna M, Klamt $F$, et al. Peripheral biomarkers and illness activity in bipolar disorder. J Psychiatr Res 2011; 45(2): 156-61.

53 Tramontina JF, Andreazza AC, Kauer-Sant'anna M, Stertz L, Goi J, Chiarani F, et al. Brain-derived neurotrophic factor serum levels before and after treatment for acute mania. Neurosci Lett 2009; 452(2): 111-3.

54 Benedict C, Scheller J, Rose-John S, Born J, Marshall L. Enhancing influence of intranasal interleukin- 6 on slow-wave activity and memory consolidation during sleep. FASEB J 2009; 23(10): 3629-36.
55 Bauer IE, Pascoe MC, Wollenhaupt-Aguiar B, Kapczinski F, Soares JC. Inflammatory mediators of cognitive impairment in bipolar disorder. J Psychiatr Res 2014; 56: 18-27.

56 Yamada K, Nabeshima T. Brain-derived neurotrophic factor/TrkB signaling in memory processes. J Pharmacol Sci 2003; 91(4): 267-70.

57 Dias VV, Brissos S, Frey BN, Andreazza AC, Cardoso C, Kapczinski F. Cognitive function and serum levels of brain-derived neurotrophic factor in patients with bipolar disorder. Bipolar Disord 2009; 11(6): 663-71.

58 McDermott KL, Raghupathi $R$, Fernandez SC, Saatman KE, Protter AA, Finklestein SP, et al. Delayed administration of basic fibroblast growth factor (bFGF) attenuates cognitive dysfunction following parasagittal fluid percussion brain injury in the rat. J Neurotrauma 1997; 14(4): 191-200.

59 de Almodovar C R, Lambrechts $D$, Mazzone $M$, Carmeliet P. Role and therapeutic potential of VEGF in the nervous system. Physiol Rev 2009; 89(2): 607-48.

60 Garcia KO, Ornellas FLM, Martin PKM, Patti CL, Mello LE, Frussa-Filho R, et al. Therapeutic effects of the transplantation of VEGF overexpressing bone marrow mesenchymal stem cells in the hippocampus of murine model of Alzheimer's disease. Front Aging Neurosci 2014; 6: 30.

61 Valente LA, Begg LR, Filiano AJ. Updating neuroimmune targets in central nervous system dysfunction. Trends Pharmacol Sci 2019; 40(7): 482-94.

62 Strawbridge R, Hodsoll J, Powell TR, Hotopf M, Hatch SL, Breen G, et al. Inflammatory profiles of severe treatment-resistant depression. I Affect Disord 2019; 246: 42-51.

63 Poletti S, Leone G, Hoogenboezem TA, Ghiglino D, Vai B, de Wit H, et al. Markers of neuroinflammation influence measures of cortical thickness in bipolar depression. Psychiatry Res Neuroimaging 2019; 285: 64-6.

64 Angelia K, Andrea V, Anna C, George D, Calin P. Abstract 223: elevated Mip-1b, peripheral arterial disease, and antiplatelet medication use predict cognitive function among asymptomatic patients referred for carotid doppler evaluation. Stroke 2015; 46(suppl 1): A223.

65 Lehto SM, Huotari A, Niskanen L, Herzig K-H, Tolmunen T, Viinamäki H, et al. Serum IL-7 and G-CSF in major depressive disorder. Prog Neuropsychopharmacol Biol Psychiatry 2010; 34(6): 846-51.

66 Aas M, Haukvik UK, Djurovic S, Bergmann $\varnothing$, Athanasiu L, Tesli MS, et al. BDNF val66met modulates the association between childhood trauma, cognitive and brain abnormalities in psychoses. Prog Neuropsychopharmacol Biol Psychiatry 2013; 46: 181-8.

67 Colasanti A, Bugiardini E, Amawi S, Poole OV, Skorupinska I, Skorupinska M, et al. Primary mitochondrial diseases increase susceptibility to bipolar affective disorder. J Neurol Neurosurg Psychiatry 2020; 91(8): 892-4.

68 Strawbridge R, Young AH. HPA axis and cognitive dysfunction in mood disorders. In Cognitive Impairment in Major Depressive Disorder: Clinical Relevance, Biological Substrates, and Treatment opportunities (ed. RS McIntyre): 179-93. Cambridge University Press, 2016

69 Miyamoto N, Maki T, Pham L-DD, Hayakawa K, Seo JH, Mandeville ET, et al. Oxidative stress interferes with white matter renewal after prolonged cerebral hypoperfusion in mice. Stroke 2013; 44(12): 3516-21.

70 Macritchie KAN, Lloyd AJ, Bastin ME, Vasudev K, Gallagher P, Eyre R, et al. White matter microstructural abnormalities in euthymic bipolar disorder. $\mathrm{Br} J$ Psychiatry 2010; 196(1): 52-8.

71 Tsai S-J. Effects of interleukin-1beta polymorphisms on brain function and behavior in healthy and psychiatric disease conditions. Cytokine Growth Factor Rev 2017; 37: 89-97.

72 Frydecka D, Misiak B, Pawlak-Adamska E, Karabon L, Tomkiewicz A, Sedlaczek $P$, et al. Interleukin-6: the missing element of the neurocognitive deterioration in schizophrenia? The focus on genetic underpinnings, cognitive impairment and clinical manifestation. Eur Arch Psychiatry Clin Neurosci 2015; 265(6): 449-59.

73 Husain MI, Strawbridge R, Stokes PR, Young AH. Anti-inflammatory treatments for mood disorders: systematic review and meta-analysis. J Psychopharmacol 2017: 31(9): 1137-48.

74 Jiang Y, Liu Y, Zhu C, Ma X, Ma L, Zhou L, et al. Minocycline enhances hippocampal memory, neuroplasticity and synapse-associated proteins in aged C57 BL/6 mice. Neurobiol Learn Mem 2015; 121: 20-9.

75 Husain Ml, Chaudhry I, Husain N, Khoso A, Husain MO, Hamirani M, et al. Minocycline and celecoxib as adjunctive treatments of bipolar depression: a multicenter, factorial design randomized controlled trial. Biol Psychiatry 2020; 87(9): S415. 